\title{
Viewpoint
}

\section{Assessing the benefits of health care: how far should we go?}

\author{
Mandy Ryan, Phil Shackley
}

The application of the techniques of economic evaluation to health care is becoming increasingly commonplace. This is shown by the increasing number of published evaluations and is to be welcomed. Despite this progress, however, we believe that current economic evaluations of healthcare interventions may fail to take into account potentially important sources of benefit and disbenefit to individual patients. If this is the case then the evaluation of many healthcare technologies will be incomplete and interventions that are thought to be efficient may in fact be inefficient and vice versa.

As we will show, empirical evidence is lacking in the economics literature to support or refute the arguments put forward in this paper (although some support can be found outside economics). In view of this, many of the issues we discuss are, to a large extent, conceptual, but this is not sufficient reason to dismiss them. In this paper we highlight the potential importance of considering a wider range of benefits in healthcare assessment to stimulate the empirical testing of the issues raised. To facilitate empirical testing we suggest two analytical techniques: willingness to pay and conjoint analysis.

\section{Is health outcome all that matters?}

To date, economic evaluation has tended to focus almost exclusively on the effects of health care on health outcome. This implicitly assumes that the only benefit to individual people of health care is improvements in health status. This assumption holds regardless of whether health status is defined narrowly - for example, in terms of combinations of disability and distress ${ }^{1}$ - or more broadly to take account of the multiple attribute nature of health. ${ }^{2-6} \mathrm{We}$ would argue that in many instances, however, people derive benefit from more than just improvements in their health status. Concentration on health outcome does not allow for the possibility of people deriving utility (welfare or satisfaction) from aspects of health care that do not directly affect their health status. Examples of such aspects are information, autonomy, dignity, and the process of treatment. We discuss these and other aspects more fully below.

The concentration on health outcome in economic evaluations is evidenced by the debate over recent years about how to measure health status. ${ }^{4-14}$ Although such work undoubtedly makes a valuable contribution to the development of economic evaluation, its focus is somewhat narrow. Of course, if health gain is all that matters to people this narrow focus is justified. However, if factors beyond health gain are important the definition of outcome may need to be extended to include these factors according to their comparative importance.

The issue is essentially establishing the aim of economic evaluation in health care. The answer most economists would give is that the aim is to ensure that scarce healthcare resources are used as efficiently as possible. But what is meant by efficiency? In economics there are various notions of efficiency, all of which incorporate some idea of maximising benefit in the face of resource constraints. The crucial question then becomes how do we define benefit? If benefit is defined purely in terms of health gain there is no problem with the current state of economic evaluation. However, if benefit is defined more broadly to include other sources of benefit besides health gain, there may be a problem. The extent of this problem will depend on the comparative importance of these other sources of benefit in relation to health gain, which will in turn depend on the service being considered.

\section{If benefit is defined purely in} terms of health gain there is no problem with the current state of economic evaluation.

\section{Patients and citizens}

The comparative importance of the various sources of benefit from health care can be determined only by the consumers of health care as only they can make the link between the consumption or availability of health care, or both, and the effects that has on their utility. However, it is important to distinguish between consumers as patients - that is, people about to consume or actually consuming health care - and consumers as citizens - that is, potential but not, as yet, patients. The sources of benefit to a person may be different depending on whether he or she is a patient or a citizen. 


\section{Benefits to patients}

INFORMATION

One possible benefit to patients of undergoing a treatment is the provision of information. In other words people may value being better informed from having participated in a healthcare programme. Much evidence from qualitative studies outside economics suggests that information is important to patients in the provision of health care. ${ }^{15}$

Some economic studies have tried to value the importance of information to patients. One such study attempted to value the information from ultrasonography in normal pregnancy using the technique of willingness to pay. ${ }^{16}$ (The principle of willingness to pay is the utility a person derives from something and is measured by the maximum amount he or she would be willing to pay for that something.) The study focused on the difference between information that has value in decision making and that which is not used for decision making. A sample of women were asked to state their willingness to pay for various items of information generated from an ultrasound scan. The items included the health of the fetus; the health of the mother; the expected delivery date; multiple pregnancy; the sex of the fetus; a visual image of the moving fetus on the screen; and a hard copy of that image. The results indicated that, on average, respondents were willing to pay a sum for the information from the scan which was over 10 times the local charge for an ultrasound test. On average, respondents allocated $74 \%$ of their willingness to pay to the decisional aspect of the information and $26 \%$ to information that was not used for decision making, suggesting that information may be valued for its own sake.

This possibility was further investigated by Lange et al (Workshop of the European Community Concerted Action, Paris, June 1990). In a study of women's willingness to pay for antenatal screening for autosomal dominant polycystic kidney disease, they found that $52 \%$ of the respondents who were willing to have the test had no intention of terminating their pregnancy if the result were positive. This suggests that there are benefits from antenatal screening other than those resulting from the termination of affected fetuses. Indeed, Mooney and Lange postulated that

for some women there is utility in reduced uncertainty or perhaps just from knowledge. ${ }^{17}$

An important conclusion from the study of Lange et al was that if the standard benefit assessment was used in the economic evaluation - that is, benefits were assumed to be restricted to the number of detected and aborted abnormal fetuses - the costs of the programme clearly exceeded the benefits Workshop of the European Community Concerted Action, Paris, June 1990). If, however, benefits were extended to include all attributes that were important to women, assessed through the willingness to pay technique, the evaluation came close to making the screening seem worth while.
The importance of information has also been investigated in the context of antenatal carrier screening for cystic fibrosis. ${ }^{18}$ Respondents were asked their maximum willingness to pay for the screening programme and also why they were willing to pay their stated amount. From the results it was not possible to say whether information was valued for its own sake. However, the women's responses showed clearly that the chance to terminate the pregnancy if the result were positive was not an overriding consideration. In other words, screening has benefits (one of which may be information) other than the opportunity to terminate.

Benefits of healthcare interventions
For patients:
Information
Reassurance
Process of treatment
Autonomy and choice
Non-medical benefits
For citizens:
Option value
Caring externality

When considering how and why information is valued by patients, it is important to consider the heterogeneity of both patients and medical treatments. In other words, the patient's desire for information may be a function both of the patient's characteristics and the type of healthcare intervention being considered. Again, work outside economics supports these hypotheses. ${ }^{15}$

\section{REASSURANCE}

Closely related to the issue of information is the value of reassurance from some healthcare interventions. Although economists have tended to overlook the value of reassurance, some researchers have looked at its importance, both qualitatively and quantitatively. For example, Gerard et al outlined several qualitative studies which suggest that there is some value in reassurance from breast cancer screening. ${ }^{19}$ Having reviewed this literature, they conclude:

Overall therefore the empirical evidence seems to suggest that attenders come to the programme with an expectation of getting some useful, reassuring information....It seems reasonable, therefore, to hypothesise that ex ante a positive value will be placed on mammography screening....

Grimes tried to value reassurance from cervical screening by asking a group of 100 women who had had a negative result in a cervical smear test how much this information was worth to them. ${ }^{20}$ The mean value of a normal smear test result was $£ 8.25$. When this sum was included in the economic evaluation of cervical smear testing the cost of each life saved through screening was substantially reduced. ${ }^{20}$ Despite its limitations, ${ }^{21}$ this study suggests that negative screening results have some value. 
The value of reassurance has also been examined in the context of screening for cystic fibrosis. ${ }^{18}$ Ninety per cent of respondents stated that reassurance from a negative screen result was of "much importance" in their reason for being willing to pay for the test. In an attempt to value this reassurance, women who received a negative result were asked whether they thought the test had been a waste of time and, if not, what was the maximum amount they would be prepared to pay for a negative screen result. The mean willingness to pay values were found to be $16 \%$ higher after they had the result than before they had the test (this difference being significant). However, the authors expressed reservations about whether estimates of willingness to pay values after having a result provide valid information. Willingness to pay after having a result is based on the certainty of having obtained a particular result (in this case a negative screening result). The authors argue that this is less realistic than the uncertain situation which confronts patients before receiving their result. Willingness to pay after having a result is almost certain to reflect reassurance and gratitude. This may have combined with the certainty of obtaining a favourable result in pushing up willingness to pay after the test.

Although screening programmes provide the opportunity for reassurance, their existence may provoke anxiety in patients, thus creating disbenefits. This anxiety may arise as a result of publicity about the screening programme; individual patients being invited to attend the programme; or positive results. Qualitative studies suggest that anxiety may arise from such factors. ${ }^{22-24}$ Of course, anxiety is often incorporated into measures of health outcome - for example, Euroqot study ${ }^{6}$ - and care must be taken to avoid double counting when anxiety is being considered.

\section{PROCESS OF TREATMENT}

Some economists argue that in addition to outcome utility, the process of treatment itself may be utility or disutility bearing. ${ }^{17}{ }^{25-28}$ In other words, people may derive utility (or more likely suffer less disutility) from the process of care. For example, taking a pill may be preferred to having an injection. Similarly, laparoscopic surgery may be preferred to more invasive open surgery.

\section{... people may derive utility ... from aspects of health care other than health outcome.}

A potential problem with process utility is deciding which aspects of process should be included in an evaluation. Should the provision of colour television sets or flowers by the bedside be included? There may be a need to determine which aspects are legitimate (C Donaldson, unpublished data). Aspects that are integral to the type of health care being considered are legitimate. For example, single rooms and autonomy are integral to National Health Service nursing homes, while noninvasiveness is integral to laparoscopic surgery and drug treatments. Colour television sets, on the other hand, are integral to none of these.

Process utility may be a misnomer, and everything included under the heading process may in fact be classified as an outcome (J Dowie, meeting of United Kingdom Health Economists' Study Group, Glasgow, June 1993). Whether or not this is the case is, we think, a secondary issue. What is more important is the recognition and acceptance that patients may derive utility (whether it be called process or outcome) from aspects of health care other than health outcome.

Despite the lack of work by economists in process utility, its potential importance is well illustrated by the considerable amount of work by other specialists over the past 20 years who have measured patients' satisfaction with the medical care they have received. Such studies have identified numerous factors that are important to patients in the process of treatment. These include humaneness; informativeness; overall quality; competence; bureaucracy; access; cost; facilities; outcome; continuity; and attention to psychosocial problems. ${ }^{29}$ Clearly, clinical outcome is just one argument in the patient's utility function. Speedling and Rose state:

$\ldots$ it is the ability of the physician to communicate concern, warmth and interest in the patient as a whole person which evokes a positive response from the patient. The physician's expertise in curing the illness is rarely seen to count more than his or her facility to care for the patient's psychosocial needs. ${ }^{30}$

From this it follows that if the clinical outcome of two types of treatment were identical, the utility from these two types of care would not necessarily be the same.

The need to consider factors beyond some medical definition of success was supported by Pfeffer and Quick in their evaluation of infertility services. ${ }^{31}$ They argue:

Factors that influence patient satisfaction.....are often not clinical but organisational and administrative.

Another example of where the process of treatment will influence the utility from health care is whether the patient leaves the treatment with dignity. For example, when evaluating healthcare interventions for patients who are terminally ill with cancer, patients' utility may be affected according to the extent to which they emerge with dignity from their treatments - even if their health status is the same. A similar argument applies to care for elderly people.

\section{AUTONOMY AND CHOICE}

Two further possible sources of (dis)utility to patients are autonomy and choice. Current economic evaluations implicitly assume that the act of choosing has no effect on utility, but this may not be so. ${ }^{32}$

One area in which consumers seem to want choice is maternity care. ${ }^{33}$ This desire for 
choice does not, however, necessarily extend to all other types of health care. Indeed, patients may prefer to delegate decision making to the doctor. Published research outside economics suggests that this may be the case. A distinction has been made by Haug and Lavin between two reasons that patients might want information from their doctors - that is, the right to medical information and the right to make medical decisions. ${ }^{34}$ As noted elsewhere, however, "they did not determine if patients desired to utilise information in order to make medical decisions." 35

The question of whether patients want to obtain medical information, and, if so, if they want to use this information to make personal medical decisions has been investigated by Beisecker and Beisecker. ${ }^{35}$ They found that, although patients want information, they tend to place the responsibility for medical decision making on the doctor. They suggest that patients

wanted to be knowledgeable about their medical care without necessarily becoming responsible for medical care decisions.

This raised the question of why it is that patients want information but prefer to defer decision making to the doctor. Is it because of the disutility from choice itself or is it, as suggested by Shackley and Ryan, ${ }^{32}$ because of the potential disutility associated with the possible outcomes of the choice? If it is the latter, then anticipated regret about the decision may be important.

Anticipated regret about a decision refers to a position in which current decisions are made in an attempt to avoid regretting later having made the wrong decision. Regret theory was first postulated by Bell and Loomes and Sugden, who argued that when people made decisions about uncertain monetary outcomes they consider not only the final assets but also the probability of experiencing regret. ${ }^{36} 37$ It is postulated that when making decisions under uncertainty, people trade off financial returns to avoid experiencing regret.

Although regret theory has been applied mainly to people's decision making when monetary rewards are uncertain, it may also explain patients relinquishing the responsibility of making a decision to their doctor. The nature of regret is such that it can only be experienced after a choice has been made. If there is no choice, there can be no regret. By relinquishing the responsibility for decision making to the presumably better informed doctor, the possibility of the patient experiencing disutility as a result of regret is eliminated. Of course, it could be argued that in deciding to let the doctor choose, the patient is still making a choice, and therefore, strictly speaking, the potential for experiencing regret is not eliminated. However, we believe that in most cases the potential regret to the patient from letting the doctor decide is considerably less than the potential regret to the patient from the patient deciding himself or herself.
Ultimately, of course, this is an empirical question.

The application of regret to patients being offered the choice of being treated with new medical technologies, specifically liver transplantation, antenatal screening, screening generally, and in vitro fertilisation has been considered by Tymstra. ${ }^{38} \mathrm{He}$ argued that the decision by patients to undergo such treatments is often influenced by feelings that

they could not refuse the chance being offered to them.... It appears that people are not inclined to turn down diagnostic or therapeutic possibilities. Refusal means that one "runs the risk of missing a positive result", something that might be regretted later.

This suggests that people deciding whether to undertake medical procedures consider the disutility that may result from making a wrong decision. Therefore, in terms of evaluating the benefits from a healthcare intervention, there may be some value in having gone through with a procedure, even if the treatment "fails." Thus, patients who have a liver transplant may feel some benefit in knowing they have done everything possible, even if the treatment fails. A recent evaluation of an assisted reproductive programme in Australia supports this supposition. ${ }^{39}$ Of 346 respondents to a questionnaire, 310 agreed with the statement, "Even if I leave (or left) the IVG/GIFT [in vitro fertilisation/gamete intrafallopian transfer] programme childless, I believe I will be (am) glad I tried it." Responses to this statement were also found to be significantly and positively related to respondents' willingness to pay for the treatments, suggesting that people derive benefit from going through the treatment even if they leave it childless.

... people deciding whether to undertake medical procedures consider the disutility that may result from making a wrong decision.

Of course, patients may regret having gone through with the treatment if it fails and so feel worse off. This possible source of disutility also needs to be addressed.

NON-MEDICAL REASONS FOR VISITING THE DOCTOR

Economists have implicitly assumed that patients are motivated to visit the doctor out of a desire to have their health status improved. However, sociological work has for many years highlighted the importance of so called nonmedical reasons for visiting the doctor. These include legitimisation of illness, pleasing someone else, or even as part of the quest to qualify for a council house. ${ }^{40-43}$ Thus, when patients visit a doctor, utility may be derived from sources other than improvements in health status. 


\section{Benefits to citizens}

OPTION VALUE AND EXTERNALITIES

Thus far, we have considered the consumer as a patient. When the consumer is considered to be a citizen, however, other sources of potential benefit can be identified - namely, option value and externalities. Option value refers to the utility obtained from having the option to use services. Utility may be derived not only for users of the service but also for current nonusers who may or may not use the service in the future. ${ }^{44}$

The notion of a caring externality in health care was first developed by Culyer. ${ }^{45}$ Only recently, however, has the potential importance of including it in economic evaluations been recognised. ${ }^{46}$ The caring externality refers to people deriving utility from the knowledge that other people are receiving health care.

To date, neither option value nor the caring externality has been included in economic evaluations in health care. We are not arguing that they should. What we are arguing is that the potential importance of including them should be investigated. Willingness to pay has been suggested as a means of measuring option value and the caring externality, but with the proviso that further development of the technique is needed. ${ }^{25}$

The views of citizens and patients may differ from or even conflict with each other. One possible conflict has been suggested by Clark and Olsen in the context of a healthcare system that is funded by individual contributions. ${ }^{47}$

\section{The views of citizens and patients may differ from or even conflict with each other.}

They suggest that as a citizen, a person will be reluctant to fund health care which provides non-health benefits but does not affect health status. However, should the same person assume the role of patient he or she would want to receive the non-health benefits. Whether this is the case is an empirical issue, worthy of further investigation.

\section{Measuring the wider range of benefits from health care}

Thus far, we have highlighted the possibility that in certain cases economic evaluations of health care interventions may fail to incorporate important sources of benefit and disbenefit to people. If this is the case, then broader measures of benefit must be developed and applied in economic evaluation. Two techniques that are worthy of further development are willingness to pay and conjoint analysis.

Few studies have used willingness to pay in a healthcare context, ${ }^{26}$ and the technique has been criticised on several grounds. For example, willingness to pay is inevitably a function of ability to pay, and the concept of having to pay for health care is a difficult one, particularly in a publicly funded healthcare system such as the British NHS. These problems must, however, be weighed against one of the main advantages of the technique, which is it allows people to value what is important to them. The value a person places on a healthcare intervention (measured in terms of their maximum willingness to pay) will depend on the perceived benefits to them of the intervention. People are not restricted to valuing improvements in health status. Rather their willingness to pay can incorporate all aspects of benefit that they believe are important. On this basis alone the technique is worthy of further development.

Conjoint analysis has its origin in mathematical psychology. Market researchers first used this technique to establish the relative importance of attributes in the provision of goods and services. ${ }^{48}$ The technique has also been used extensively in transport economics to establish the importance of such attributes as fare, time, comfort, speed, etc, in choices about alternative modes of transport. ${ }^{49}$ It is also gaining widespread support in environmental economics, and the use of the technique to establish users' valuations of quality in the provision of public services was recently recommended by the Treasury. ${ }^{50}$ However, the application of conjoint analysis to health care has, to date, been limited..$^{51-55}$

The technique entails presenting people with hypothetical scenarios comprising different levels of various attributes that have been identified as being important, and asking them to rank, rate, or make pairwise choices between the scenarios. These data can be used to establish the relative importance of different attributes in the provision of a product or service; the optimal way of providing a product or service; and the change in utility (or satisfaction) from moving from one type of product or service to another. For example, Ryan and Farrar were concerned with the trade offs people make between waiting time and location of clinic (central or local) for orthodontic services. ${ }^{51}$ Respondents were presented with a number of pairwise choices comprising different levels of waiting time and alternative locations and asked to state their preference within each choice. The utility scores showed that waiting time was by far the most important attribute. The recommendations of the study were therefore that future policy should concentrate on reducing waiting time rather than introducing local clinics.

The application of the technique to health care has great potential. By including such aspects as information, degree of autonomy, aspects of process, etc, as attributes in a conjoint analysis, it is possible to establish whether they are important to people. Furthermore, if they are found to be important, their relative importance can also be ascertained. Ryan has reviewed the technique of conjoint analysis in detail..$^{56}$

\section{Conclusion}

We think that economic evaluation as currently applied to healthcare technologies may fail to take into account all important sources of benefit to people. As has been demonstrated 
in the studies by Lange et al and Grimes (Workshop of the European Community Concerted Action, Paris, June 1990), ${ }^{20}$ failure to include such benefits can have significant effects on the outcome of an evaluation. However, the comparative importance of health and non-health benefits to patients and society as a whole has yet to be established. There are clearly costs both in measuring nonhealth benefits more thoroughly and in funding care that generates non-health benefits as opposed to health gains. The current underemphasis on non-health benefits may reflect the fact that society attaches more importance to health gains than non-health benefits, in which case the costs of measuring and investing in non-health benefits may not be considered worth while. Given that the relative trade offs have yet to be established, however, this remains an empirical issue, but one which clearly warrants further investigation.

If the case for considering a wider range of benefits is accepted two further issues need to be addressed. The first is the question of how to measure and value such benefits for inclusion in economic evaluation. We suggest that willingness to pay and conjoint analysis are two possible techniques for doing this.

The second issue relates to the possible resource allocation and ethical implications of including such benefits in an economic evaluation. To illustrate this, consider an example of a screening programme that detects a condition at a stage at which there is no beneficial treatment in terms of improvements to health status. If health gain is assumed to be the only benefit from screening the programme would be unlikely to receive funding. However, if the screening programme is valued for other reasons - for example, it provides valuable information or reassurance, or both - then, assuming these benefits can be measured, an economic evaluation might recommend that the programme be funded; in other words, the benefits are deemed to be greater than the resource costs. From an ethical point of view, however, it is often argued that screening should be provided only if an effective treatment for the condition is available. The issue is then raised of what should be done in these circumstances. We emphasise at this stage that the results of economic evaluations are only one input into the decision making process. Other factors must also be considered - for example, ethics and equity. We think that decisions about health care should be informed and that healthcare policy should not be made under the assumption that all that matters is health gain. If non-health benefits are important to people policy makers need to be made aware of that fact. If economic evaluation continues to ignore non-health benefits then policy will continue to be made on the basis of incomplete information, which may lead to detrimental effects on efficiency and quality of care.

We thank Jan Abel Olsen of the University of Tromsø and two nonymous referees for valuable comments on earlier drafts of this paper. The Health Economics Research Unit is funded by the Chief Scientist Office of the Scottish Office Home and Health Department, but the opinions expressed in this paper are ours alone.
1 Kind P, Rosser R, Williams A. Valuation of quality of life: some psychometric evidence. In: Jones-Lee MW, ed. The value of life and safety. Amsterdam: Elsevier/North The value of life

2 Torrance G, Zhang Y, Feeny D, Furlong W, Barr R. Multiattribute preference functions for a comprehensive health status classification system. Hamilton, Ontario: McMaster University, 1992. (Centre for Health Economics and Policy Analysis Working Paper No 92-18.)

3 Torrance G. Measurement of health state utilities for economic appraisal. Fournal of Health Economics 1985; 5:1-30.

4 Feeny D, Torrance G, Goldsmith C, Furlong W, Boyle M. A multi-attribute approach to population health status. for Health Economics and Policy Analysis Working Paper No 94-5.)

5 Carr-Hill R. Health related quality of life measurement Euro style. Health Policy 1992;20:321-8.

6 Euroqol Group. Euroqol - a new facility for the measurement of health-related quality of life. Health Policy 1990;16:199-208.

7 Culyer AJ, Wagstaff A. QALYs versus HYEs. Fournal of Health Economics 1993;11:311-23.

8 Gafni A. The quality of QALYs (quality-adjusted-lifeyears): do QALYs measure what they at least intend to measure? Health Policy 1989;13:81-3.

Loomes G, McKenzie L. The use of QALYs in health care decision making. Soc Sci Med 1989;28:299-308.

10 Mehrez A, Gafni A. Quality-adjusted life years, utility theory, and healthy-years equivalents. Med Decis Making 1989;9:142-9.

11 Mooney G, Olsen J. QALYs: where next? In: McGuire A, Fenn P, Mayhew K, eds. Providing health care: the economics of alternative systems of finance and delivery. economics of altermative systems of finance

12 Nord E. An alternative to QALYs: the saved young life equivalent (SAVE). BMF 1992;305:875-7.

13 Rawles J. Castigating QALYs. F Med Ethics 1989;15:143-7. Williams A. Economics

15 Ryan M. Agency in health care: lessons for economists from sociologists. American foumal of Economics and Sociology 1994;53:207-17.

16 Berwick D, Weinstein M. What do patients value? Willingness to pay for ultrasound in normal pregnancy. Med Care 1985;23:881-93.

17 Mooney G, Lange M. Ante-natal screening: what constitutes benefit? Soc Sci Med 1993;37:873-8.

18 Donaldson C, Shackley P, Abdalla M, Miedzybrodzka Z. Willingness to pay for antenatal carrier screening for cystic fibrosis. Aberdeen: University of Aberdeen, 1993. (Health fibrosis. Aberdeen: University of Aberdeen, 1993. (H

19 Gerard K, Turnbull D, Lange M, Mooney G. Economic evaluation of mammography screening: information, reassurance and anxiety. Aberdeen: University of Aberdeen, 1992. (Health Economics Research Unit discussion paper 01/92.)

20 Grimes D. Value of a negative cervical smear. BMf 1988;296:1363.

21 Cairns J, Shackley P. Sometimes sensitive, seldom specific: a review of the economics of screening. Health Econ 1993;2:43-53.

22 Dean C, Roberts M, French K, Robinson S. Psychiatric morbidity after screening for breast cancer. $\mathcal{F}$ Epidemiol Community Health 1986;40:71-5.

23 Elkind A, Eardley A. Consumer satisfaction with breast screening: a pilot study. $\mathcal{f}$ Public Health Med 1990; 12:15-8.

24 Wright C. Breast cancer screening: a different look at the evidence. Surgery 1986;100:594.

25 Donaldson C. Theory and practice of willingness to pay for health care. Aberdeen: University of Aberdeen, 1993. (Health Economics Research Unit discussion pape 01/93.)

26 Gerard K, Mooney G. QALY league tables: handle with care. Health Econ 1993;2:59-64.

27 McGuire A, Henderson J, Mooney G. The economics of health care: an introductory text. London: Routledge and Kegan Paul, 1988.

28 Ryan M. Economic evaluation of in vitro fertilization: examining the benefits. Aberdeen: University of Aberdeen, 1992. (Health Economics Research Unit discussion paper 13/92.) (Health Economics Research Unit discussion paper 13/92.) 1991;302:887-9.

30 Speedling E, Rose D. Building an effective doctor-patient relationship: from patient satisfaction to patient relationship: from patient satisfaction
participation. Soc Sci Med 1985;21:115-20.

31 Pfeffer N, Quick A. Infertility services: a desperate case. London: Greater London Association of Community

32 Shackley $P$, Ryan $M$. What is the role of the consumer in health care? Fournal of Social Policy 1994;23:517-41.

33 House of Commons Health Committee. Second report maternity services. London: HMSO, 1992.

34 Haug MR, Lavin B. Practitioner or patient - who's in charge? f Health Soc Behav 1981;22:212-29.

35 Beisecker AE, Beisecker TD. Patient information-seeking behaviour when communicating with doctors. Med Car 1990;28:19-28.

36 Bell D. Regret in decision making under uncertainty. Operations Research 1982;30:961-81.

37 Loomes G, Sugden R. Regret theory: an alternative theory of rational choice under uncertainty. Economic fouma 1982;92:805-24. 
38 Tymstra $T$. The imperative character of medical technology and the meaning of "anticipated decision regret." Int $f$ Technology Assess Health Care 1989;5:207-13.

39 Ryan M. Using economics to assess the benefits of assisted reproductive techniques. Aberdeen: University of Aberdeen, 1994. (Health Economics Research Unit discussion paper 04/94.)

40 Lupton D. Consumer sovereignty or blissfull ignorance? Consumerism in health care [thesis]. Sydney: University of Sydney, 1990

41 Tuckett D. Doctors and patients. In Tuckett D, ed. An introduction to medical sociology. London: Tavistock, 1976.

42 Tudor-Hart, J. The inverse care law. Lancet 1971;i:405-12.

43 Turner B. Medical power and social knowledge. London: Sage, 1987.

44 Weisbrod B. Collective-consumption services of individualconsumption goods. Quarterly fournal of Economics 1964; 78:471-7.

45 Culyer AJ. The nature of the commodity health care and its efficient allocation. Oxford Economic Papers 1971; 24:189-211.

46 Labelle R, Hurley J. Implications of basing health care resource allocations on cost-utility analysis in the presence of externalities. Fournal of Health Economics 1992;11:259-77.

47 Clark D, Olsen JA. Agency in health care with an endogenous budget constraint. Fournal of Health Economics 1994;13:231-51.
48 Cattin P, Wittink D. Commercial use of conjoint analysis: a survey. Fournal of Marketing 1982;46:44-53.

49 fournal of Transport Economics and Policy 1982.

50 Brunel University. The valuation of changes in quality in the public services. Report prepared for HM Treasury. London: HMSO, 1993.

51 Ryan M, Farrar S. Using conjoint analysis to establish the views of users in the provision of orthodontics in Grampian. Economics Research Unit discussion paper.)

52 Propper C. Contingent valuation of time spent on NHS waiting list. Economic fournal 1991;100:193-9.

53 Harwood R, Rogers A, Dickinson E, Ebrahim S. Measuring handicap: the London handicap scale, a new outcome measure for chronic disease. Quality in Health Care 1994;3:11-6.

54 Maas A, Stalpers L. Assessing utilities by means of conjoint measurement: an application in medical decision analysis. Med Decis Making 1992;12:288-97.

55 Verhoef C, Maas A, Stalpers L, Verbeek A, Wobbes TH, van Daal $W$. The feasibility of additive conjoint measurement in measuring utilities in breast cancer patients. Health Policy 1991;17:39-50.

56 Ryan M. Stated preference: a method for establishing the nature of the patient's utility function. Aberdeen: University of Aberdeen 1992 (Health Economics Research Unit discussion paper 14/92.) 